\title{
RELIGION: VOICE OF THE MULTI-VOICED SELF - VALUATING THE DIVERSITY OF RELIGIOUS AND NON-RELIGIOUS PHILOSOPHIES OF LIFE AS PART OF THE MULTI-VOICED SELF
}

\author{
Ina ter Avest \\ CHN University, Leeuwarden \\ Cok Bakker \\ Utrecht University \\ The Netherlands
}

\begin{abstract}
In this article we focus on a newly developed Dutch method of introducing pupils and students into the religious dimension of the various subjects of the school curriculum. We call this method of Religious Education (RE): Lessons in Apprehension (LiA). The innovative aspect lies in the awareness of personal commitment in addition to knowledge about various religious traditions as they are experienced in the present Dutch society. The development of commitment is an important task in identity development. The narrative perspective on identity fits inherently with the valuation theory and is historically rooted in this theory. The theoretical concepts of the valuation theory are at the base of the Lessons in Apprehension; lessons that aim at awareness and understanding of the role of religion and the religious dimension of school subjects. The pilot project shows that the method of LiA offers good opportunities to arrive at what Marcia (1982) has called Identity Achievement.
\end{abstract}

Key Concepts: Innovative, personal commitment, diversity, identity, multi-voiced self

\section{Dutch Society}

The image the Dutch culture evokes at the beginning of the twenty-first century is that of a continuous transitional process. In the second half of the previous century, the Netherlands changed from being a static monocultural society into a dynamic multicultural society. In the fifties of the preceding century, we refer to Dutch society as a pillarised society. At that time society was organised along religious frontier lines. What at first glance seemed to be a homogeneous culture, on closer inspection required a more shaded description. Dutch society was homogeneous in the field of ethnicity. Simultaneously a certain degree of heterogeneity was discernible as several (sub-) cultures existed alongside each other. They distinguished themselves by a (whether or not religious) difference in philosophical beliefs. Diversity occurred particularly in the area of religion. This plurality was shaped in the form of a construction of building bricks - constituent parts of the larger entity of a society build upon Christian and liberal values (Vermeulen, in: Merks and Beck, 1997; Bakker and Ter Avest in this journal).

The secularisation and the process of individualisation are factors often mentioned as causal for the multicultural society, but the aspect of de-institutionalisation also had an influence. Yet another influence was the arrival of migrant workers from the southern part 
of Europe, from Turkey and the northern part of Africa. The confrontation with the otherness of the guest workers and their other religion, the Islam, also brought to the surface the plurality within the Dutch society. At this moment the Islam ranks as the second religion in line behind Christianity. Islam is furthermore a growing religion in regards to number of believers and in respect of growing attention and interest, especially in the media.

\section{Dutch Educational System}

The pillarisation of Dutch society is still evident within the Dutch educational system at the beginning of the twenty-first century. In the Netherlands religion and denomination play an important role in the layout of the educational system. Similar to the pillarised society, the Dutch educational system is also known as a pillarised system, which means that it is based on religious dividing lines. In the Netherlands there is denominational education i.e. Protestant and Roman-Catholic schools, as well as public and private schools. Under the influence of the secularisation process, the pillarisation in society has become less visible; in fact, in some sectors it has completely disappeared.

In the Netherlands the multiculturalisation of society has led to the introduction of the school subject Spiritual and Ideological Movements (SIM). The goal of this subject is to inform the pupils about any set of coherent answers to existential questions. During these lessons teachers inform their pupils and students - according to their phase of psychological development - on the various religious and non-religious spiritual movements in Dutch society. The lessons aim at the development of a sensibility to the different ways in which people fulfil their spiritual needs (Mittendorff and Verbeek, 1991:11). The aim of these lessons fits into the main targets of basic training in the Netherlands. These targets mention the importance of a certain attitude and behaviour of openness towards the other and the acceptance of the values other people stand for. English literature refers to this fashion of philosophical education with the term: Teaching about (Grimmitt, 2000). The crux of the subject is the transfer of knowledge of spiritual movements. The training in SIM is also a common part of the teacher training. Apart from the national curriculum, the Teacher Training Colleges for Roman-Catholic and Protestant teachers educate their students for certification in Religious Education (RE).

\section{Dutch Society: Multicultural and Multireligious}

The multicultural society is a reality. More than a mere reflection of society, the multicultural society manifests itself in the classroom. Intercultural learning highlights the variations on the important themes of the culture. To prepare students for a life as a citizen in a multicultural society, that harbours adherents of various spiritual movements, a form of dialogical education was developed. Students learn from collective stories and from their fellow-students. Under the guidance of their teacher and with their peers, students explore their experiences and look for similarities and articulate differences in their interpretations. This form of philosophical education is referred to with the concept of supervised openness (Ter Avest, 2003:329).

For the purpose of this type of education a method and a manual were developed to stimulate students to explore their commitment towards the various collective stories, religious as well as non-religious, both individually and in a group. The method is founded on the valuation theory and the Self Confrontation Method (SCM; Hermans and HermansJanssen, 1995). We call this method Lessons in Apprehension (LiA). Before we steep ourselves into the valuation theory and the SCM, we will describe identity development as 
a narrative. Necessarily so, as the valuation theory is based on the basic metaphor of the person as a motivated storyteller.

\section{Narrative Identity}

Concerning identity development, a basic understanding of this narrative approach is that the individual gets to know him- or herself in the story. According to Crossley (2000) the basic principle of narrative psychology is that individuals come to understand themselves through the medium of language, through talking and writing. The story provides the narrator with an opportunity to structure the events experienced in daily life. As the storyteller speaks newly acquired information intertwines with expertise already present and thus the knowledge transforms into a new element in the biography of the storyteller. Consequently, the identity of a unique person is created all the time. Although he will never be the same, he remains the same one. People articulate and imag(e)-ine their identity in a continuing process of story telling. Identity is a narrative, an end-less story. By telling the story repeatedly the person creates an order in the endless amount of incidents and events, thus bringing forth a meaningful and manageable coherence in his identity. This personal life-story will never be a dry enumeration of facts, but instead an interlacement of selected true and partly (at times completely) invented events and encounters, along with the corresponding feelings and judgments whether certain goals are worth striving for. A person will never succeed in attaining everything he aims at, yet the story offers the possibility of fitting failure into life. The life-story is and always will be a construction of the individual. Speech and writing are activities during which people constantly create their own story and accordingly their identity. Crossley states that this is the way persons create themselves.

The development of a student being educated at a Teachers' Training College can be described as a change in perspective to a changing reality (Breeuwsma, 1999). The developmental psychologist Marcia (1984) speaks of a change in degree of commitment to situations, persons and stories in his or her contact. Part of the identity development is the integration of collective stories in the personal life history. Collective stories are voices of the multivoiced Self.

An important aspect of the identity development of a student of a Teachers' Training College is the professional component. The teacher as an educator is one of the voices in the multi-voiced Self of the person, and so is the teacher as a trainer and as a designer of educational processes. The lovely and successful teacher is also a voice, as is the strict and rigid teacher. In addition, another voice is the collective expectation $(s)$ of society, concerning the professionalism of the teacher. In the process of autobiographical reflection, the student learns to move flexible from one voice to another. This flexibility is an essential characteristic of the professional.

The narrator develops the personal story by placing his own story next to already existing ones and converting it in a process of intercreation. Conspicuous experiences motivate the person to reiterate his story. The identity of an individual is not a static entity. What I am as a Self, my identity, is essentially defined by the way persons and things bear significance to me. Moreover, my self-interpretation can be defined only in relation to other people, an interchange of speakers (Taylor, 1989). The life-story is constantly reiterated, and consequently rewritten. Unpredictable and unexpected matters, new information and know-how, new collective stories the person gets to know - all this is integrated in his lifestory into a coherent whole. The narrator develops the personal story by placing his own 
story next to already existing ones and restructures it in a process of intercreation. Conspicuous experiences (critical incidents and critical persons) motivate the person to reiterate his story. A pupil as well as a student is a motivated storyteller (Hermans, 1995:1). Identity emerges from this storytelling.

The contextual approach forms the background of identity as a narrative. Identity develops in the context of collective stories: The story of culture and its values and regulations, and the religious stories being part of the culture. The person listens to these stories and gives them meaning in the way he shows himself committed towards (parts of) these stories.

\section{The Task of Teachers' Training Colleges in Identity Development}

In the plan of action of a lectureship on Identity Development at School we find the statement: A core task of education is contributing to the personal education of students, i.e. their identity development (Volman, 2003). We interpret identity as a narrative process of the person that is related to a common cause transcending personal interest and thus leads to self-realisation (Alma, 1998:279). In this context Fowler (1981) emphasises the significance of the group in the identity development process. He states that students need a group to converse perpetually, to fantasise about the future, to share each other's optimism and worries, to pay attention to one another and to have the opportunity to be known and accepted. With the aid of her peer group, the student can scrutinise her personal outlook on (professional) life, her philosophy of life. This encompasses the ability to reflect upon concrete situations and applied skills in the personal professional practice (reflective professional), as well as the ability to situate this practice in the context of her personal development against the background of current debate in the educational system (Hammersley, 1999). This dialogical process is of vital importance to the profiling of the personal as well as the professional identity (Hermans, 1995).

The most important task in adolescence is becoming who you are, together with others. Becoming who you are concerns the autonomy of an individual; together with others stimulates the awareness of mutual dependency and care. Becoming who you are also concerns the acknowledgement of the uniqueness and the value each child is provided with by its parents. Together with others you can become who you are. The voices of the educators resound throughout this process. We refer to this as the multi-voiced Self.

In the process of becoming who you are, the school shows a mirror image of the diversity of the multicultural society. The task and responsibility concerned compel her to make explicit, in the framework of professional interpretation of her job, the matters that in her personal development often remain implicit. The process of (professional) identity development takes place in the space between the identity as primary school teacher in training and the abstract notion as part of the collective story of society: The professional profile or prototype of the primary school teacher.

During the training the reflection on the acts of the teacher and her actions in the classroom, and in the team setting, is a key factor in the learning process. However, the reflection needs to penetrate the more profound layers. Following Korthagen (2002) we refer to this as core reflection. As Korthagen distinguishes between perceptible behaviour and underlying skills and beliefs in his model of layers of personality, Kelchtermans (2001), in turn discerns immanent and transcendent reflection. Immanent reflection analyses the experiences of actions in class and aims at improving them; it is a naturally pragmatic and utilitarian process. Transcendent reflection intends to clarify the student's 
commitment to the underlying values, such as creativity, solidarity, and humanity in the way they are related to the other, the pupil or the colleague. Such an interpretation of reflection signifies a search for the affective aspect of the action. Underlying values and the sub sequential positive and negative involvement of the student are significant in the process of reflection, so that the student is connected to her professional activities in both mind and body - and with heart and soul.

The Self Confrontation Method (SCM) of Hermans particularly complements the reflection methodology of Korthagen in respect to the bestowal of meaning and the affective involvement of the student. Korthagen's idea of core reflection focuses on the feelings evoked in the phase of awakening to the target position and the restrictions inhibiting its actualisation. The SCM structures the exploration of these feelings related to the emotions of the moment reflected upon. The SCM is both a diagnostical and a development-stimulating instrument, integrating collective stories into the narrative of the life-story. The newly developed instrument of LiA elaborates on the concept of SCM.

\section{Identity Development and the Valuation Theory}

The SCM is based on the valuation theory. The theoretical framework, the valuation theory, is rooted in the metaphor of the person as a motivated storyteller (Hermans and HermansJansen, 1995:1). In this theory the concepts of Self and the multi-voicedness of the Self occupy a central position. Hermans (1987) describes the concept of Self as an organised system of valuations. The term valuation in the valuation theory means that the storyteller gives a certain valuation to (a part of) his life-story or a collective story. These parts of his life-story are formulated in so-called valuations, compact sentences describing critical incidents (Kelchtermans, 1994).

The use of terminology in the valuation theory implies that Hermans departs from the notion that an individual is related to the events, situations, stories and people in his life in a specific manner, namely an interpretive and valuating one - either positive or negative. Hermans distinguishes two fundamental motives in human existence. The first is the socalled S-motive, directed at the reinforcement of personal strength and defence of the personal domain. The second is called the O-motive and is directed towards the other; involvement and solidarity with other people or organisations. According to Hermans this also encompasses religious orientations like the feelings of a bond with God. Positive as well as negative feelings bridge the gap between the manifest events and the latent motivations underlying them.

The good primary school teacher is an abstract notion in the collective story of our culture. The student's image of the good primary school teacher contains all the personal experiences, impressions and associations of a student concerning education. Following Kelchtermans, we call this complex the subjective educational theory of the student. The scoring of the affect-terms reveals the patterns in the affective commitment to the different valuations. The confrontation with the affect-patterns reveals the interrelatedness between different valuations of the biography. This clarifies and articulates the subjective educational theory of the student and sheds some light on the sort and direction of the commitment to the professional identity of the teacher(-student). The moment the reconstructed pattern of action coincides with the internalised expectations prevalent in society, is referred to by Mead as self-realisation or spiritual or meaningful experience (in: Alma, 1998:49). 


\section{Lessons in Apprehension (LiA)}

The confrontation and self-examination, as outlined above in the valuation theory and the $\mathrm{SCM}$, is the point of departure for the tool we developed for application in RE classes of students in secondary and higher education. A lesson in Apprehension (LiA) is meant to stimulate in a dialogical process the religious identity being a dimension of the identity development.

The three most important features that a simplified and educationally applicable SCMversion will have to encompass are the following:

- the process of awareness is set in motion, in an inter-personal dialogue as well as in an intra-personal dialogue;

- the external and internal dialogue results in an insight in one's own involvement with (religious) philosophical and ethical issues addressed in the educational context (the so called diagnostic function of the SCM);

- pupils and students need to be challenged to bring up their own stories, the so-called provocative function;

- the thus developed insight provides the student with leads to arrive at self-control of the learning process (meta-reflective skills; the so-called development stimulating function of the SCM).

This SCM in its dialogical operating procedure will stimulate the student to expand his personal comfort zone (Vygotskij, 1978). The SCM focuses on the cognitive and (positive as well as negative) affective aspects of the attitude of the student. This implies that teachers are interested in the external (social world) as well as the internal sources (complexity in philosophy of life) of the student. Student and teacher together examine the way in which these sources can positively contribute to the process of professional identity development. The teacher is educated and trained to influence the sources in the environment of the student, the situation in which learning takes place. Teachers ought to know how to arrange the learning environment of the student in a way that benefits the exploration - even of their own perspective on the world.

Learning situations can only be classified as such if they evoke students' desire to explore further. Setting out in a search implies a susceptibility to find or to be found. Finding always has an element of the unexpected and of surprise; the search will lead us to places we rarely if ever visit, and there are no guarantees that our search will lead to the desired result. To find something that was lost adds certain lustre. Even when we do not find what we were looking for, we could stumble upon an unexpected finding just as valuable or even more so (serendipity) (Alma, 1998:85). The SCM creates such a learning situation to explore further. In the following paragraph we will elaborate on this model and $\mathrm{LiA}$ as a method, which consists of four phases aiming at awareness and insight. We present as an example the pilot study involving pupils from a secondary school, as well as students from a Teachers' Training College. ${ }^{1}$

\footnotetext{
For an extensive theoretical underpinning of the translation of the extensive SCM into a simplified version and instrument for application in an educational setting, see: TJ van den Knippenberg and H Schilderman, $O p$ Verkenning, Tilburg, 1999.
} 


\section{Phases in Apprehension}

Phase 1

In the first phase of the model, the subject is introduced as a series of Lessons in Apprehension. What is stressed is that the aim of these lessons is not to form an opinion on the subject, nor to be able to make a clear and profound statement on the topic. The accent -which is stressed - is on the exploration of the personal attitude and the affective commitment towards a variety of aspects of the central subject of these lessons.

In a Teachers' Training College the start of a series of lessons on Adaptive Didactics constituted the first phase of LiA. This first phase was especially focused on the theme of diversity as part of Classroom Management. Every teacher-student was requested to recall a moment at which she sincerely intended to address the diversity in her classroom and simultaneously sensed a lack of control over the pupils. These dialogues gave rise to a shared critical incident - a shared valuation. Every student fills in a form with affect-terms, like joy and anger, to learn about his personal commitment to this shared valuation.

\section{Phase 2}

In the second phase a variety of collective stories is presented to the students. The stories stem from different spiritual traditions or (religious and non-religious) philosophies of life, shedding some light upon the different interpretations on the theme of the series of lessons, being diversity. In this phase, the students examine what these stories mean to them on a personal level and what kind of feelings they evoke. They fill in the form with positive and negative affect-terms.

If we ask the students what things mean to them, we are in fact asking about the relations and connections to something else in their personal life history. Crossley (2000) refers to this as the perceptual openness of people. Relations are the building stones of the determination of meaning. In collective stories such relations and processes are stored throughout generations. All together they provide a certain order of meaning.

\section{Phase 3}

In the third phase of the instrument the students analyse their personal positive and negative scores. For every statement the students total up the positive and negative marks separately. Those two totals added up give an impression of his or her personal commitment to a certain philosophy of life as stated in the collective or so-called offered valuation. The commitment is the result of positive or negative feelings. The students compare the scores of the collective valuation to the valuation as it was formulated in the first phase, which will give an impression of relatedness or deviation from the offered valuation based on a philosophy of life. Subsequently, pupils or students in pairs compare the ways in which they filled in the scoring lists. The students inquire about the meaning of each other's scores. They asked each other why one person filled in a five for joy while another student scored a two for the same feeling, and how they arrived at that score.

These type of questions prime the external dialogue on the significance attached to the feelings as scored in the list. Students will feel free to question each other and listen to the clarification of each other, provided that the teacher has created a safe atmosphere. A safe classroom climate is a necessity for students to be able to perceive and hear what is said and meant to be said. The teacher is a facilitator in this process of reflection process, by asking stimulating, open questions. 
After this comparison in pairs the next step is the comparison with the group average. It will provide them with food for thought about the way they either correspond with, or deviate from the group average, and the manner in which they deviate. This will provide ample points of contact for further discussion, for example on the degree of tolerance for deviation in the group.

\section{Phase 4}

The last phase offers the student the opportunity to further explore or elaborate on the subject. The student can do so by means of, for instance, a project to map out or visualise how the various spiritual narratives and (religious or non-religious) philosophies of life helped him fathom the theme and comprehend the meaning the theme has in her own life.

\section{Concluding and Critical Remarks}

In the preceding paragraphs we informed about the phases of LiA - an accommodated version of the SCM as an instrument to provoke the intra- and interpersonal dialogue on commitment towards religious and nonreligious philosophies of life - related to topical subjects.

The pilot project showed that pupils and students appreciate this tool for reflection upon their commitment. They like to fill in forms to learn about themselves. The activity resembles filling in forms in youth magazines in which they learn about their personality: Being introvert or extravert, being a person having a high or low IQ. This natural attraction to the method facilitates the transition to a more unfamiliar subject like philosophies of life.

From the point of view of constructivism the philosophical learning process does not just happen to the student but instead is actively brought about by the construction of a personal meaning to situations and events. Cognitively and affectively the student relates herself to the new situation or event, the supplied teaching material and to matters already learned. Therefore the teacher's assignment is to activate the student to awareness and construction of meaning. For philosophical learning to occur, a condition is that the teacher applies activating didactics. Activating didactics stimulate the student to transform and create knowledge which is closely related to his personal involvement. LiA make a meaningful contribution in this area.

In order to be able to share the religious dimension of the experience it is an imperative to develop communicative skills for the (inter)religious dialogue. Only then can interreligious learning lead to more than just the acquaintance with the official theological doctrines. Activating didactics stimulate the pupil and the student to be involved personally and to transform and produce new knowledge. LiA make a meaningful contribution in this area.

Next to the concept-logical language - so dominant in our culture - the development of metaphor competency as an aspect of religious literacy is of the utmost importance in RE. Sensitivity towards the symbolic function of objects and stories is a conditio sine qua non. In opposition to the concept-logical approach Van Aalsem (2000) refers to this as an imagelogical approach. In the pilot project this appeared to be a skill not quite mastered by all the teachers. Other teachers displayed a lack of communicative skills and had trouble in handling the changing role from teacher to facilitator. As one of them stated: I was used to giving the right answers to students asking questions; now I was forced to ask the right questions. 
In the scoring list used in the pilot study we noticed a significant difference between $\mathrm{LiA}$-version and the original and far more extensive version of the SCM. More research is needed to explore the possibilities of a SCM-version which allows for group-reflection on the central motives of the valuation theory: The basic motives of self-enhancement ( $\mathrm{S}$ motive) and other-relatedness (O-motive) in an educational context.

The process of reflection described above in the Lessons of Apprehension, stresses, unlike the reflection of skills (Teachers' Training College), the reflection of the whole person of the teacher/educator (Pedagogical Centre). The combination of the theoretical framework of the reflection method of Korthagen, the biographical method of Kelchtermans and the valuation theory of H. Hermans (resulting in the SCM as a method of stimulating the attention for the personal narrative) honours the pedagogical assignment of educational institutions for teachers. The diversity in the Dutch multicultural society - its multi-voiced-ness - is honoured in this newly developed model for RE. The inter-religious dialogue between representatives of various religions in the classroom also occurs as an intra-religious dialogue in the person internally. To accommodate this process pupils and students need to learn about (religious or non-religious) philosophies of life in order to learn from it and construct their own worldview. The Dutch-Turkish politician Fadime Örgu refers to this process by the term intercreation. In the interaction, in the intercultural society, a novelty is created that resemblance to anything, and is a continuous work in progress. LiA contribute to this work in progress.

As a serious threat for RE we notice the lack of the individual religious education and socialisation of the teachers in their past and consequently the lack of their religious literacy. Teachers themselves may be ignorant of the various spiritual traditions and (religious and non-religious) philosophies of life. They may be religiously illiterate and consequently unable to facilitate the process of apprehension in their students. That is probably the main problem we have to tackle in the future of RE. Thus we will have to start with teaching the teacher - educating the educators.

\section{BIBLIOGRAPHY}

Alma, H 1998. Identiteit door verbondenheid, Een godsdienstpsychologisch onderzoek naar identificatie en christelijk geloof. Kampen: Uitgeverij Kok.

Avest, Ina ter, 2003. Kinderen en God, verteld in verhalen, Een longitudinaal onderzoek naar de ontwikkeling van het godsconcept van autochtone en allochtone kinderen in een multiculturele en multireligieuze onderwijscontex. Zoetermeer: Boekencentrum.

Bakker, C 1999. Diversity as Ethos in Intergroup Relations. Diversity as Ethos, ICRSA, Cape Town: University of Cape Town. South Africa.

Breeuwsma, G 1999. De constructie van de levensloop. Boom Amsterdam: Meppel.

Crossley, ML 2000. Introducing narrative psychology, Self, trauma and the construction of meaning. Buckingham - Philadelphia: Open University Press.

Fowler, JW 1981. Stages of Faith. New York: Harpert Collins Publishers.

Gergen, K and Gergen M 1983. Narratives of the self Studies in social identity, eds. Sarbin TR \& Scheibe K. New York: Praeger. 54-74.

Grimmitt, M 2000. Pedagogies of Religious Education, Case Studies in the Research and Development of Good Pedagogic Practice in RE. Essex, Great Wakering: McCrimmon Pulbishing Co Ltd. 
Hermans, HJM and Hermans-Jansen E 1995. Self Narratives, The construction of meaning in Psychotherapy. New York, London: The Guilford Press.

Kelchtermans, G (nd.) De professionele ontwikkeling van leerkrachten vanuit het biografisch perspectief. Nederlands Tijdschrift voor Opvoeding, Vorming en Onderwijs. 15(3) 126-139.

Korthagen, FJ 2001. Waar doen we het voor: op zoek naar de essentie van goed leraarschap. IVLOS, Universiteit Utrecht.

Marcia, JE 1985. The identity status approach to ego identity. Ego identity: Handbook for psychosocial research, (eds.) Marcia, JE, Waterman, AS \& Matteson, DR. Hillsdale: Lawrence Erlbaum.

Merks, KW and Beck, HL (eds.) 1997. Religieus pluralisme, Dynamiet of dynamiek? Amsterdam: Ambo.

Mittendorf, M and Verbeek, C 1991. Geestelijke Stromingen, een modern leergebied, Onderwijskundige brochuren reeks. Tilburg: Zwijsen.

Pollard, A 1997. Reflective Teaching in the Primary School, A Handbook for the Classroom. Cassell Education, London/New York: Continuüm.

Taylor, C 1991. The Ethics of Authenticity. Massachusetts and London: Harvard University Press, Cambridge.

Volman, M 2003 Beleidsplan lectoraat 'Identiteit in het onderwijs'. Nijmegen: Interne publicatie HAN.

Vygotskij, LS 1997. Educational Psychology. Florida: CRC Press LLC. 